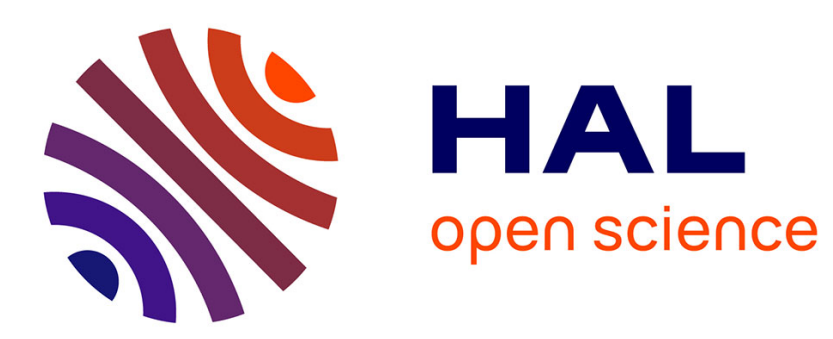

\title{
Urbanization and Agricultural Structural Adjustments: Some Lessons from European Cities
}

Walid Oueslati, Julien Salanié, Junjie Wu

\section{To cite this version:}

Walid Oueslati, Julien Salanié, Junjie Wu. Urbanization and Agricultural Structural Adjustments:

Some Lessons from European Cities. 2014. halshs-01098773

\section{HAL Id: halshs-01098773}

https://shs.hal.science/halshs-01098773

Preprint submitted on 29 Dec 2014

HAL is a multi-disciplinary open access archive for the deposit and dissemination of scientific research documents, whether they are published or not. The documents may come from teaching and research institutions in France or abroad, or from public or private research centers.
L'archive ouverte pluridisciplinaire HAL, est destinée au dépôt et à la diffusion de documents scientifiques de niveau recherche, publiés ou non, émanant des établissements d'enseignement et de recherche français ou étrangers, des laboratoires publics ou privés. 


\section{Urbanization and Agricultural Structural} Adjustments:

Some Lessons from European Cities

Walid Oueslati, Julien Salanié, JunJie Wu

December 2014 


\section{GATE Groupe d'Analyse et de Théorie Économique Lyon-St Étienne}

93, chemin des Mouilles 69130 Ecully - France

Tel. +33 (0)4 72866060

Fax $+33(0) 472866090$

6, rue Basse des Rives 42023 Saint-Etienne cedex 02 - France

Tel. +33(0)4 77421960

Fax. +33 (0)4 77421950

Messagerie électronique / Email : gate@gate.cnrs.fr

Téléchargement / Download : http://www.gate.cnrs.fr - Publications / Working Papers 


\title{
Urbanization and Agricultural Structural Adjustments: Some Lessons from European Cities
}

\author{
Walid Oueslati ${ }^{1}$, Julien Salanié, ${ }^{2,3}$ and JunJie $\mathrm{Wu}^{4}$ \\ ${ }^{1}$ Agrocampus-Ouest, Department of Economics, Management and Society, France \\ ${ }^{2}$ Université de Lyon, Lyon, F-69007, France ; CNRS, GATE Lyon Saint-Étienne, Écully, F-69130, \\ France \\ ${ }^{3}$ Université Jean Monnet, Saint-Étienne, F-42000, France \\ ${ }^{4}$ Department of Applied Economics, Oregon State University, Corvallis, USA
}

December 7, 2014

\begin{abstract}
:
Urbanization presents both opportunities and challenges to agriculture. This paper analyzes the effect of urbanization on the structure and profitability of agriculture at the rural-urban fringe. We develop a theoretical model accounting for changes in the amount of urban development, the level of fragmentation, and population density associated with urbanization. We show that urbanization not only affects the land allocation between traditional and highvalue crops, but also changes relative input and output prices for the two types of crops. We conduct an empirical analysis to estimate the effect of increasing population density and urban fragmentation on farm returns for a set of European metropolises using a Bayesian averaged model that deals with model uncertainty. Our results show that increasing population density increases farm returns while increasing land fragmentation may have a detrimental effect in the beginning but a positive effect for high levels of fragmentation.
\end{abstract}

Keywords: Farmland, urban sprawl, farm profitability, urban development patterns.

JEL classification: O18, R14. 


\section{INTRODUCTION}

Although agriculture remains the main user of rural land in many European countries, the amount of farmland has declined, on average, by $4 \%$ among the European countries over the last two decades, and this decline is projected to continue (EEA, 2006). Most of the farmland loss occurs at the urban fringe on high-quality farmland. Many blame low-density and noncontiguous development, commonly known as urban sprawl, as a primary cause of farmland loss.

There are at least three major concerns over the continuing farmland loss. First, the conversion of the most fertile farmland to development reduces agricultural productivity, which decreases food supply in the short run and threatens food security in the long run. Second, farmland development reduces amenities and quality of life in rural communities. Third, farmland loss may have a detrimental effect on agricultural infrastructure. As the total amount of farmland reduces below a certain threshold, the local agricultural support sector, such as input suppliers or output processors, may lose their businesses because of insufficient demand for their output or insufficient supply of input for their production. Consequently, agricultural economies will shrink in the short run and may become unviable in the long run.

Alongside these concerns, opportunities also arise from increasing urbanization. The emergence of a new customer base provides opportunities for higher value crops. The rapid increase in the number of nurseries, vegetable farms, vineyards, and other high-value crops in many suburban areas shows that farmers have remarkable adaptability and capacity to adjust their enterprises to take advantage of the proximity to urban centers.

The role of agriculture and urbanization has always been at the heart of the debate on sustainable land use patterns in a modern economy. The purpose of this paper is to explore the interactions between urbanization and agriculture at the fringe of cities. To achieve this objective, we first develop a theoretical model to analyze the interrelationship between agriculture and its supporting sectors and then examine how the relationship is affected by increasing urbanization, characterized by more land development, more fragmentation, and increasing population density. We then conduct an empirical analysis to evaluate the effect of urbanization on local agricultural economies using city-level data from 282 large urban zones in Europe. 
Numerous studies examine how urbanization affects agricultural activities. It is worth noting that farms at the urban fringe are likely to be intensive in terms of non-land inputs. Land conversion expectations and development irreversibility generate a growth premium and an option value which decrease with distance from the city and make up the agricultural component of farmland prices (Capozza \& Helsley, 1989, 1990). Many empirical investigations in the U.S. and Europe show that both of these factors explain the observed negative gradient of farmland prices away from the city (Plantinga et al., 2002; Cavailhès \& Wavresky, 2003; Livanis et al., 2006; Wu \& Lin, 2010).

As urban development increases, land use conflicts are likely to be more severe at the urban fringe. This may lead to an increase in local regulation designed to force farmers to internalize some of the negative externalities generated by agriculture (Lisansky 1986). Lockeretz (1986) examined the characteristics of counties by their distance to metro areas and found that counties closer to metro areas tend to have smaller farm sizes, a higher proportion of harvested cropland, a higher standard of living, and more reliance on crops than livestock. In a later study, Lockeretz (1989) examined agricultural trends in US Midwestern counties at varying distances from metropolitan centers and found that metropolitan counties experienced the most rapid decrease in the amount of farmland. However, loss of farmland was partially offset by increasing intensity.

Lopez et al. (1988) analyzed the effects of suburbanization on agricultural production choices, prices, and profits. They found that although some subsectors of agriculture, such as vegetable production, may benefit from urbanization, others are adversely affected. They concluded that the overall impact on profits is positive when capital gains on land are included. Gardner (1994) found that a $100 \%$ increase in the population resulted in an $11 \%$ decrease in farmland in metro counties in the Northeast United States. Larson et al. (2001) reported that more than half the value of total U.S. farm production was derived from counties facing urbanization pressure. Lynch and Carpenter (2003) examined whether the farm sector has a critical mass by estimating three econometric models using data from six Mid-Atlantic States. Rashford et al. (2003) developed a simulation model to analyze the degree of economic interconnectedness among neighboring farms and to assess the impact on neighboring farms when one farm in a small farming area is converted to alternative land uses. Wu et al. (2011) examined the effect of urbanization on agricultural infrastructure and 
on the cost and profitability of farming in the U.S. West Coast. They concluded that agriculture related opportunities of urbanization outweigh the challenges, leading to an overall positive effect on net return.

In this paper, we add new insights to the existing literature by analyzing the effect of several dimensions of urban development on local agricultural infrastructure and net return to farming. These dimensions include total developed area, the level of land fragmentation and population density. Theoretically, we show that these dimensions often have opposite effects. Our empirical results show that these dimensions affect farm returns in a non-linear fashion and should be accounted for in urban planning policies. In compactly developed areas, policies that increase population density and, at the same time, prevent urban fragmentation will increase agricultural productivity. Although much research has examined the effect of urbanization on agriculture in the United States, relative little research has focused on this issue in Europe and we also contribute to fill this gap.

The remainder of this paper is organized as follows. Section II presents a theoretical model to analyze the effect of urbanization on local agricultural economies. Section III specifies the empirical model based on the theoretical analysis and discusses the strategies for estimating the model. Section IV discusses data and methodological issues related to the measurement of urbanization. Section V presents the empirical results. Section VI highlights some policy implications. Section VII concludes.

\section{THE MODEL}

Consider a local agricultural economy facing increasing urban encroachment. The emergence of a new customer base with urbanization provides opportunities to grow high-value crops such as flowers and vegetables. But increasing farmland fragmentation and potential conflicts with non-farm neighbors and stringent environmental regulation make farming more costly at the urban fringe. In addition to these technical externalities, urbanization can affect farmers by affecting the input and output prices. For example, with urban development, the total farmland acres will decrease. As a result, the demand for agricultural input such as fertilizer and seeds will decrease. As the demand decreases below a certain threshold, the nearest input supplier will close its business. The farmer will have to pay more or travel longer distance for input. Likewise, as the total farmland acreage drops below a certain threshold, the nearest 
processor may close its business, and farmers will have to accept lower output prices or pay additional transportation costs for their output. This suggests that even if individual farmers may have a constant return to scale technology, at an aggregate level, there may be scale economies in farming.

To examine the structural changes associated with urbanization, we present a simple model to capture both the positive and negative effects of urbanization at the rural-urban fringe. Let $\bar{L}$ be the total land area in the region, which can be used for agriculture $(A)$ or urban development $(U): A+U=\bar{L}$. Agricultural land can be used to produce a traditional crop (called corn henceforth) or a high-value specialty crop (called vegetable), with $i=c, v$ indicating the two crops.

$$
A_{v}+A_{c}=\bar{L}-U
$$

where $A_{v}$ and $A_{c}$ denote the total acreage of vegetable and corn, respectively. Corn is traded in the international market, and the demand for corn is perfectly elastic, thus corn price is exogenous from the region's perspective. Vegetable, in contrast, is sold primarily in the local market, and its price is determined by local demand and supply.

Let $\pi_{i}\left(p_{i}, w_{i}\right)$ denote the per-acre profit from growing crop $i$, where $p_{i}$ is the output price, and $w_{i}$ is the input price. $\pi_{i}\left(p_{i}, w_{i}\right)$ has all the standard properties, including convexity in $p_{i}$ and $w_{i}$. By Hotelling's rule, the per-acre input demand and output supply for crop $i$ equal $x_{i}\left(p_{i}, w_{i}\right) \equiv-\frac{\partial \pi_{i}}{\partial w_{i}}$ and $y_{i}\left(p_{i}, w_{i}\right) \equiv \frac{\partial \pi_{i}}{\partial p_{i}}$, respectively. Thus, the total demand for agricultural input for crop $i$ in the region equals $A_{i} x_{i}\left(p_{i}, w_{i}\right)$, and total supply of crop $i$ in the region equals $A_{i} y_{i}\left(p_{i}, w_{i}\right)$. Input demand is assumed to be more elastic with respect to input price than output supply (because of availability of input substitute), but less elastic with respect to output price (i.e., $\varepsilon_{w_{i}}^{x_{i}} \equiv-\frac{w_{i}}{x_{i}} \frac{\partial x_{i}}{\partial w_{i}} \geq \varepsilon_{w_{i}}^{y_{i}} \equiv-\frac{w_{i}}{y_{i}} \frac{\partial y_{i}}{\partial w_{i}} ; \varepsilon_{p_{i}}^{x_{i}} \equiv \frac{p_{i}}{x_{i}} \frac{\partial x_{i}}{\partial p_{i}} \leq \varepsilon_{p_{i}}^{y_{i}} \equiv \frac{p_{i}}{y_{i}} \frac{\partial y_{i}}{\partial p_{i}}$ ).

Let $Y_{v}^{d}\left(p_{v}, D, U,\right)$ denote the demand for vegetable, which decreases with vegetable price and increases with total developed area $U$ and population density $D$ in the region. The equilibrium vegetable price is determined by 


$$
A_{v} y_{v}\left(p_{v}, w_{v}\right)=Y_{v}^{d}\left(p_{v}, D, U\right)
$$

Let $X_{i}^{s}\left(w_{i}\right)$ denote the supply of agricultural input for crop $i$. Equilibrium in the input market requires:

$$
A_{i} X_{i}\left(p_{i}, w_{i}\right)=X_{i}^{s}\left(w_{i}\right), i=c, v
$$

Individual farmers are price takers in both the input and output markets. But their collective land use decisions affect the aggregate demand for input and the total supply of output, which, in turn, affect the input and output prices.

Farmers allocate their land between alternative uses to maximize profit, taking into account the transaction costs. Transaction costs may include the cost and pain of learning to grow a new crop. Even if it is more profitable to grow a high-value crop, farmers may not be willing to make additional investment because of the impermanence syndrome (Lopez, Adelaja and Andrews 1988). Increasing farmland fragmentation associated with urbanization likely exacerbates the impermanence syndrome. Thus, the additional profit needed for farmers to switch to the high-value crop, $\Delta$, depends on the degree of fragmentation $(S)$. The equilibrium land allocation ensures

$$
\pi_{v}\left(p_{v}, w_{v}\right)=\pi_{c}\left(p_{c}, w_{c}\right)+\Delta(S) .
$$

Equations (1)-(4) constitute the equilibrium conditions that define the agricultural land allocation $\left(A_{c}, A_{v}\right)$ and input and output prices $\left(p_{v}, w_{v}, w_{c}\right)$ as a function of $S, D$, and $U$. Comparative static analysis using these equations with respect to $S$ gives the effect of fragmentation on land allocation and input and output prices, which are summarized in the following proposition.

Proposition 1 (Effects of increased farmland fragmentation). The following results hold if and only if $\Delta^{\prime}(S) \geq 0$ :
a) $\frac{\partial A_{v}}{\partial S} \leq 0$,
b) $\frac{\partial A_{c}}{\partial S} \geq 0$,
c) $\frac{\partial p_{v}}{\partial S} \geq 0$,
d) $\frac{\partial p_{c}}{\partial S}=0$
e) $\frac{\partial w_{v}}{\partial S} \leq 0$,
f) $\frac{\partial w_{c}}{\partial S} \geq 0$, 

g) $\frac{\partial \pi_{v}}{\partial S} \geq 0$
h) $\frac{\partial \pi_{c}}{\partial S} \leq 0$.

Proof: see appendix 1.

Proposition 1 suggests that if increasing farmland fragmentation increases the profit margin needed for farmers to switch to the high-value crop, it will reduce the amount of land allocated to the high-value crop. This will reduce the input price and increase the output price for the high-value crop. Consequently, the per-acre profit from growing the high-value crop will increase with fragmentation. In contrast, increasing fragmentation will increase the amount of land allocated to the traditional crop and thus will increase the demand for the total input for the crop. Thus, the input price for the traditional crop will increase with fragmentation. Because the price of the traditional crop is determined in the international market, increasing fragmentation will reduce its per-acre profit. The average profit per acre of farmland can increase or decrease with fragmentation, depending on the level of the transaction cost (i.e., $\Delta(S)$ ) and its sensitivity with respect to fragmentation (i.e., $\Delta^{\prime}(S)$ ).

Although fragmentation makes farming more challenging, a large consumer base will create opportunities for marketing the high-value crop. Comparative static analysis using equations (1)-(4) with respect to the total urban area $U$ gives the following results:

Proposition 2 (Effects of increasing urban development).
a) $\frac{\partial A_{v}}{\partial U} \geq 0$,
b) $\frac{\partial A_{c}}{\partial U} \leq 0$,
c) $\frac{\partial p_{v}}{\partial U} \geq 0$,
d) $\frac{\partial p_{c}}{\partial U}=0$,
e) $\frac{\partial w_{v}}{\partial U} \geq 0$,
f) $\frac{\partial w_{c}}{\partial U} \leq 0$,
g) $\frac{\partial \pi_{v}}{\partial U} \geq$ or $\leq 0$,
h) $\frac{\partial \pi_{c}}{\partial U} \geq 0$.

Proof: see appendix 1. 
In contrast to the effect of farmland fragmentation, increasing demand for vegetable associated with urbanization will lead to more land allocated to the high-value crop. Despite the increased supply, the price of vegetable will increase. However, because of the increasing demand for input at both the intensive margin (due to increased vegetable price) and the extensive margin (due to increased acreage of vegetable), the input price of vegetable also increases with increasing urban development. Consequently, the per-acre profit for vegetable can increase or decrease. Because less land will be allocated to producing the traditional crop, the total demand for input for the crop will decrease, which will lead to lower input price and higher per-acre profit for the traditional crop.

With increasing urbanization, the population density may also increase. Comparative static analysis using equations (1)-(4) with respect to the population density $D$ gives the following results:

Proposition 3 (Effects of increasing population density).
a) $\frac{\partial A_{v}}{\partial D} \geq 0$
b) $\frac{\partial A_{c}}{\partial D} \leq 0$
c) $\frac{\partial p_{v}}{\partial D} \geq 0$
d) $\frac{\partial p_{c}}{\partial D}=0$
e) $\frac{\partial w_{v}}{\partial D} \geq 0$
f) $\frac{\partial w_{c}}{\partial D} \leq 0$
g) $\frac{\partial \pi_{v}}{\partial D} \geq$ or $\leq 0$
h) $\frac{\partial \pi_{c}}{\partial D} \geq 0$

Proof: see appendix 1.

Proposition 3 shows that increases in population density have similar effects, at least, qualitatively, as increases in total developed area. Specifically, increasing population density raises the demand for the high-value crop, which will lead to a higher price and more land allocated to the production of the crop. Because of the increasing demand for input at both the intensive and extensive margins, the input price of vegetable also increases. In contrast, because less land will be allocated to producing the traditional crop, the demand for input for the traditional crop will decrease, which will lead to a lower input price and higher per-acre profit for the traditional crop. 
Equations (1)-(4) define land allocation $\left(A_{c}, A_{v}\right)$ and input and output prices $\left(p_{v}, w_{v}, w_{c}\right)$ as a function of $S, D$, and $U$. This implies that the average per-acre net return to agriculture in the region, $\pi=\left(A_{c} \pi_{c}+A_{v} \pi_{v}\right) /\left(A_{c}+A_{v}\right)$, is also a function of $S, D$, and $U$ :

$$
\pi=f(S, D, U)
$$

In many case, urbanization will lead to both increased farmland fragmentation $S$ and a larger customer base (i.e., larger $D, U$ ). Propositions 1-3 show that these two changes often have opposite effects, except that they both increase the price of the high-value crop. Thus, urbanization can have a positive or a negative effect on local agricultural infrastructure and farm profit. If urbanization has little effect on the demand for the high-value crop, less land will be allocated to the high-value crop and the average per-acre net return to agriculture will likely decrease with urbanization, even if per-acre profit from growing the high-value crop will increase. On the other hand, if urbanization increases the demand for the high-value crop, but does not significantly increase farmland fragmentation, it will increase the price of the high-value crop and the share of cropland allocated to the crop. In this case, the average peracre net return to agriculture will likely increase with urbanization. In the following sections, we will conduct an empirical analysis to measure the effects of urbanization on farming in European metropolises.

\section{EMPIRICAL MODEL AND ESTIMATION STRATEGY}

We evaluate the impact of urbanization on farm returns using an empirical counterpart to (5) for a sample of European cities:

$$
\pi_{i}=\alpha+\sum_{k=1}^{K} \beta_{k} X_{k i}+\varepsilon_{i}
$$

where $\pi_{i}$ is a measure of farm returns in city $i$ and $X_{k i}$ a vector of $K$ candidate covariates including proxies for urban development $\left(U_{i}\right)$, population density $\left(D_{i}\right)$ for city $i$. Since we are especially interested in the effects of development patterns, $X_{k i}$ also contains covariates describing fragmentation $\left(S_{i}\right)$. 
From Propositions 1-3, the effect of urban development on farm returns can be either positive or negative. In addition, the relationship between farm returns and urbanization may well exhibit nonlinearities and threshold effects. We introduce these nonlinearities by incorporating squared terms of the variables of interest. In a closely related paper, Wu et al. (2011) show that in the U.S., net farm income per farmland acre first decreases and then increases with $U_{i}$, while it increases with $D_{i}$. This last result is consistent with Livanis et al. (2006). It is also consistent with Duvivier (2013) who shows that Chinese farmers close to urban areas are more efficient than those farther away. However, most of the covariates introduced by $\mathrm{Wu}$ et al. (2011) to explain farm returns (e.g. wages in other sectors, median population income, population's education, etc.) were not significant. We thus face an important uncertainty about what the "true" model looks like.

To deal with this model uncertainty, we rely on a Bayesian model averaging (hereafter BMA) approach to estimate (6). Detailed discussions of BMA can be found in Raftery et al. (1997), Hoeting et al. (1999), and Wasserman (2000). Here, we summarize some key points of this approach.

BMA is particularly suited for estimation and inference problems where we are uncertain of which model to choose on strong empirical evidence or theoretical grounds. Rather than choosing a single model, on a goodness-of-fit or information criterion, to represent the knowledge we have on the process under study, BMA proposes to average over a wide range of models weighted by their posterior probability as in (7).

$$
P\left(\beta_{k} \mid \Phi\right)=\sum_{j=1}^{2^{K}} P\left(\beta_{k} \mid \Phi, M_{j}\right) P\left(M_{j} \mid \Phi\right)
$$

where $P\left(\beta_{k} \mid \Phi\right)$ is the posterior distribution of parameter $\beta_{k}$ given data $\Phi . P\left(\beta_{k} \mid \Phi, M_{j}\right)$ is the posterior distribution of parameter $\beta_{k}$ given data $\Phi$ and model $M_{j}$, and $P\left(M_{j} \mid \Phi\right)$ is the posterior probability of model $M_{j}$ given the data $\Phi . P\left(M_{j} \mid \Phi\right)$ is the weighting term in (7) which reflects the strength of empirical evidence in favor of model $M_{j}$. The summation is done over the entire models space. Here, we have $K$ candidate covariates to enter (6) which leads to $2^{K}$ potential models. Using Bayes theorem, we have (8): 


$$
P\left(M_{j} \mid \Phi\right)=\frac{P\left(\Phi \mid M_{j}\right) \cdot P\left(M_{j}\right)}{P(\Phi)}=\frac{\int P\left(\Phi \mid \beta_{k}, M_{j}\right) P\left(\beta_{k} \mid M_{j}\right) d \beta_{k} \cdot P\left(M_{j}\right)}{\sum_{l}^{2^{K}} P\left(\Phi \mid M_{l}\right) P\left(M_{l}\right)}
$$

where $P\left(\Phi \mid \beta_{k}, M_{j}\right)$ is the likelihood of the data given model $M_{j}$ and parameters $\beta_{k}$, $P\left(\beta_{k} \mid M_{j}\right)$ is the prior density of $\beta_{k}$ under model $M_{j}$ and $P\left(M_{j}\right)$ is the prior probability of model $M_{j}$. The denominator in (8) is the sum of marginal likelihoods over the entire models space.

Amongst the difficulties to overcome in BMA, one needs to $(i)$ manage the summation in (7), ${ }^{1}$ (ii) compute the integrals in (8), and (iii) choose prior distribution of models $P\left(M_{j}\right)$ in (8). Assume for now that these difficulties are overcome, then we can describe the posterior distribution of parameters by their posterior mean and variance given by (9) and (10) respectively (Hoeting et al. 1999):

$$
\begin{gathered}
E(\hat{\beta} \mid \Phi)=\sum_{j=1}^{2^{K}} \hat{\beta}_{j} \cdot P\left(M_{j} \mid \Phi\right) \\
\operatorname{Var}(\hat{\beta} \mid \Phi)=\sum_{j=1}^{2^{K}}\left(\operatorname{Var}\left(\hat{\beta} \mid \Phi, M_{j}\right)+\hat{\beta}_{j}{ }^{2}\right) P\left(M_{j} \mid \Phi\right)-E(\hat{\beta} \mid \Phi)^{2}
\end{gathered}
$$

where $\hat{\beta}_{j}=E\left(\hat{\beta} \mid \Phi, M_{j}\right)$.

(i): To handle the summation in (7), a solution is to restrict model space to a subset of the "best" models. It is possible to search model space using a Markov chain Monte Carlo of model composition algorithm (Madigan and York 1995). In this algorithm, the Markov chain is built by transiting to new models that are close in terms of specification and having a better posterior probability than the model defining the current state of the chain. Another possibility is to adopt an ad hoc rule for adding models to the pertinent subset of model space. Madigan and Raftery (1994) have proposed an Occam's window approach which we will follow in this paper. In this approach, the subset of pertinent models, labeled $\bar{M}$, includes only models whose posterior odd falls within a threshold distance. The posterior odd between two models is the ratio of the posterior probability of those models (Kass and Raftery 1995). Hence, suppose that we already have a good model $M_{0}$, then a candidate model $M_{1}$ will be included

\footnotetext{
${ }^{1}$ With 30 potential covariates, one would have $2^{30}$, i.e. more than a billion models to sum over.
} 
in $\bar{M}$ only if $P\left(M_{0} \mid \Phi\right) / P\left(M_{1} \mid \Phi\right) \leq C$, where $C$ is the threshold distance for rejection. Kass and Raftery (1994) suggest to take $C=20$ as a rule of thumb, which means that we should only include in $\bar{M}$ the models that are at least 20 times less probable than our best identified model. Another rule is to exclude all $M_{1}$ submodels once it has been excluded. Additionally, if two models $M_{l}$ and $M_{s}$ are nested, $M_{l}$ being the longer model, then $M_{l}$ is excluded ${ }^{2}$ if it is less supported by the data than the simpler model $M_{s}$, that is if $P\left(M_{s} \mid \Phi\right) / P\left(M_{l} \mid \Phi\right)>1$. Following this approach allows us to restrict the subset of pertinent model $\bar{M}$ to only a few models. (7) can then be replaced by $P\left(\beta_{k} \mid \Phi\right)=\sum_{\bar{M}} P\left(\beta_{k} \mid \Phi, M_{j}\right) P\left(M_{j} \mid \Phi\right)$.

(ii) and (iii): To compute the integral and choose the prior distribution in (8), recall the first equality in (8) and see that the posterior odd between two models $M_{0}$ and $M_{1}$ is given by (11):

$$
\frac{P\left(M_{0} \mid \Phi\right)}{P\left(M_{1} \mid \Phi\right)}=\frac{P\left(\Phi \mid M_{0}\right)}{P\left(\Phi \mid M_{1}\right)} \frac{P\left(M_{0}\right)}{P\left(M_{1}\right)}
$$

If $M_{0}$ and $M_{1}$ are equally probable a priori, that is if $P\left(M_{0}\right)=P\left(M_{1}\right)$, then (11) simplifies to $P\left(M_{0} \mid \Phi\right) / P\left(M_{1} \mid \Phi\right)=P\left(\Phi \mid M_{0}\right) / P\left(\Phi M_{1}\right)$ where the right-hand side of this equality is known as the Bayes factor. Kass and Raftery (1995) have shown that the Bayes factor can be asymptotically approximated using the Bayesian information criterion (BIC). Kass and Wasserman (1995) show that this corresponds to the unit information prior where all models are a priori on equal footage (i.e. when they have the same prior probability). Then, it is possible to show that (e.g., Raftery 1995) that (12) approximates (8).

$$
P\left(M_{k} \mid \Phi\right) \approx \frac{e^{-B I C_{k} / 2}}{\sum_{l \in \bar{M}} e^{-B I C_{l} / 2}}
$$

where $B I C_{l}$ is the Bayesian information criterion measured for model $M_{l}$ which, considering a linear model, is equal to $B I C_{l}=n \log \left(1-R_{l}^{2}\right)+\operatorname{dim}\left(M_{l}\right) \log n$ with $R_{l}^{2}$ being the coefficient of determination of model $M_{l}$ and $\operatorname{dim}\left(M_{l}\right)$ its dimension (i.e., the number of parameters).

\footnotetext{
${ }^{2}$ Kass and Raftery (1995) refer to this as Occam's razor considering that between two equivalent models, the most parsimonious should always be selected.
} 
BMA of linear models has some interesting features. First, using simulations, Raftery et al. (1997) shows that BMA outperforms other classical specification search methods, such as stepwise or adjusted- $R_{l}^{2}$, in selecting the true model, even when the covariates are correlated or when the true model is the null. Second, the average model can be used for predictions. It has a better predictive accuracy than any other single model (Hoeting et al., 1995). These two features are particularly appealing because we are interested in finding empirical evidence on the role of urbanization on farm returns and on simulating some policy scenarios on urban development.

\section{DATA}

Data for this study come from several sources. We focus on a sample of European cities obtained by combining various existing data sources. Our starting point was the complete set of 320 cities used in the Urban Audit (UA) database. ${ }^{3}$ Here, all cities are defined at three scales: the Core city, which encompasses the administrative boundaries of the city; the Large Urban Zone (LUZ), which is an approximation of the functional urban region centered around the Core city; and the Sub-City District, which is a subdivision of the LUZ (EUROSTAT, 2004). We concentrate on LUZs, because farmland development is observed around the fringes of cities. Therefore, the boundaries of each LUZ define the spatial units upon which this study is based.

UA provides rather limited information on land use, with poor coverage for many cities. As an alternative to this data set, we use data on Urban Morphological Zones (UMZ), compiled by the European Environment Agency (EEA), which contains spatial information. Derived from Corine Land Cover, UMZ data covers the whole EU-27 at a 200m resolution for those urban areas that considered contributing to urban tissue and function (Guerois et al., 2012). Geospatial data on agricultural and non-agricultural areas for each city in 2006 is obtained by superimposing the LUZ boundaries on the UMZ spatial data, using a Geographical Information System (GIS). To illustrate the nature of the spatial data, Figure 1 provides maps documenting the urban (artificial) area for four selected cities: Kielce and

\footnotetext{
3 The Urban audit database arises from a project coordinated by Eurostat that aims to provide a wide range of indicators of socio-economic and environmental issues. These indicators are measured across four periods: 19891993, 1994-1998, 1999-2002, 2003-2006. For further details, refer to: http://epp.eurostat.ec.europa.eu/portal/page/portal/region_cities/city_urban.
} 
Radom (Poland), Eindhoven (Netherlands), and Murcia (Spain). The external boundary is shown in grey. The fragments of urban land within the boundaries are represented by the black patches.

The UA data is supplemented using data obtained from the European Observation Network, Territorial Development and Cohesion (ESPON). ${ }^{4}$ When combined, these data sources provide a set of explanatory variables covering a broad sample of European cities. Direct measures of per-acre farm net returns are unavailable for our large sample of European cities. We use agricultural added value per unit of agricultural land (AGRICPROX) to approximate farm returns. Although this proxy reflects more agricultural productivity, it provides a good indicator of farming performance in each city. Data on agricultural added value were obtained from ESPON, and the relevant data on agricultural land area for each LUZ were calculated from the UMZ spatial data.

We construct variables to measure the amount of urban development, the level of fragmentation, and population density. The total artificial area in square kilometers (ARTIFAREA) is considered as a proxy for all urbanized land in each LUZ. These areas were obtained directly from the spatial UMZ data according to Corine Land Cover nomenclature. This simple measure reflects the evolution of urban land use in a given area without any prejudgment on internal composition or urban morphology (i.e., the scattered nature of the urban area).

We construct an index to reflect urban morphology, in particular, the degree of fragmentation of urban area. The index, which is referred to as the fragmentation index and denoted by FRAG, is calculated by FRAG = FRAGMENTS/ARTIFAREA, where FRAGMENTS represents the number of urban fragments (i.e., individual urban patches) within a specific LUZ. We divide FRAGMENTS by the artificial area within each LUZ to correct for the size effect, since we expect that larger urbanized areas will have more fragments. Figure 1 illustrates the calculation of FRAGMENTS for 4 cities in the sample.

\footnotetext{
${ }^{4}$ ESPON is a European research program, which provides pan-European evidence and knowledge about European territorial structures, trends, perspectives, and policy impacts which enables comparisons amongst regions and cities. For further details, see: http://database.espon.eu/.
} 


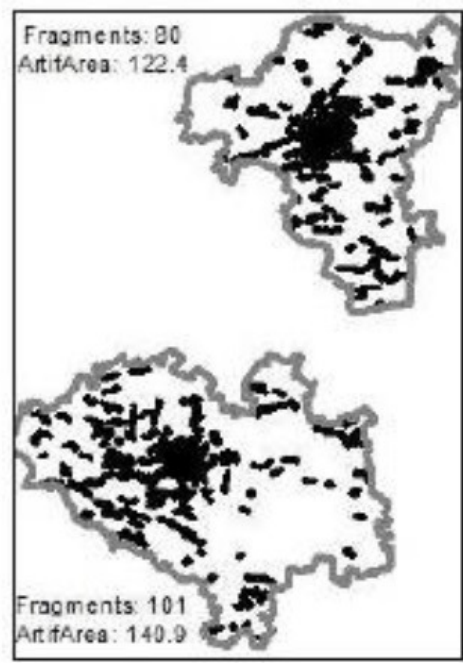

Kielce \& Radom (Poland)

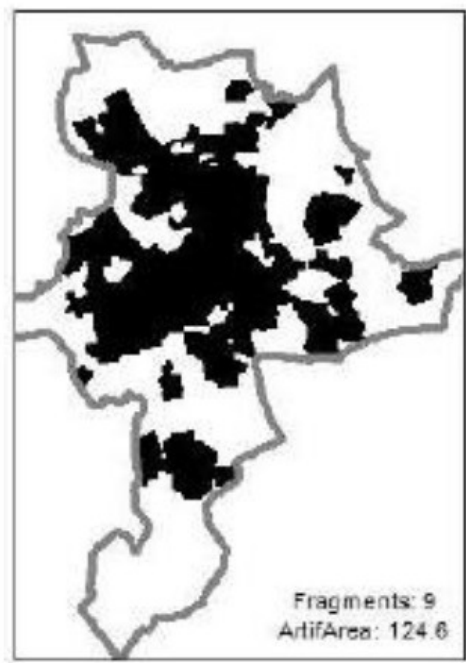

Eindhoven (Netherlands)

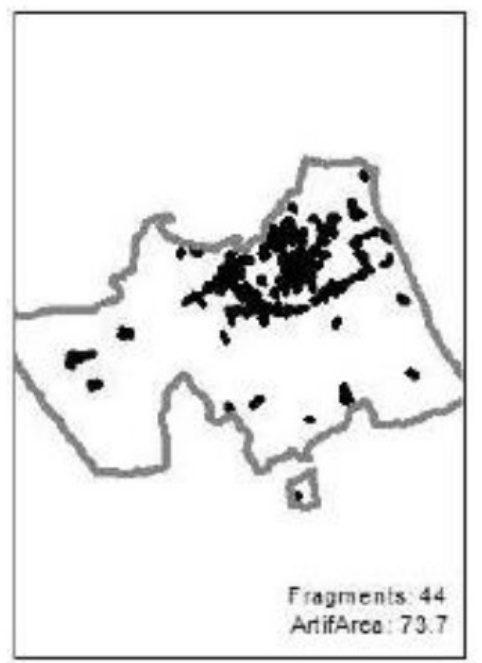

Murcia (Spain)

Figure 1. Illustration of the urban fragments counting

Population density (DENSITY) is calculated by dividing total population by the total artificial area. Total population for each city is obtained from the ESPON database. The ESPON database also provides comprehensive data for each LUZ on Gross Domestic Product (GDP) adjusted for Purchasing Power Standards and total population $(P O P){ }^{5}$ We use GDP per capita $\left(G D P \_C A P\right)$ as a proxy for income that influences consumers' demand for highvalue crops.

Furthermore, we added a set of climatic and environmental data collected from the Urban Audit. The climatic variables include the number of rainy days per year $(R A I N)$ and the average temperature of the warmest month in a year (TEMPERATURE). The environmental variables include the annual average concentration of $\mathrm{NO}_{2}(\mathrm{NO} 2)$ as a good indicator of air pollution in the cities. A terrain variable, median city centre altitude above sea level $(M E D A L T)$, is also included. This variable is a partial indicator of the ruggedness of the LUZ's terrain which may have an impact on the potential for urban growth. We use highway density (HIGHWAY) from the Eurostat regional data set as a proxy for transport costs. The implicit assumption here is that investments in highways make traveling faster and more convenient, which reduces the time and the costs of commuting.

In addition to the economic and geographical variables of interest, various other social and cultural variables are considered. First, data on recorded crime (CRIME) from the Urban

\footnotetext{
${ }^{5}$ Total population represents all residents who have their residence within the LUZ.
} 
Audit is used to account for the security situation in the central city. As mentioned previously, Patachini and Zenou (2009) find that higher crime rates increase sprawl. Second, we include the number of cinema seats (CINEMA) as a proxy for the cultural attractiveness of the central city. A vibrant central city would be expected to discourage decentralization, thus reducing sprawl and resulting in more compact urban areas.

We gathered partial data on 282 European cities. Considering the availability of agricultural added value and the coverage of Corine Land Cover for 2006, we are left with 208 observations. ${ }^{6}$ Yet, we don't have information on all potential covariates for each city. The list of potential covariates under study, their definition, and the number of cities for which they are available are presented in Table 1.

\section{EMPIRICAL RESULTS}

Before turning to the BMA estimation, we explored simple models relating agricultural added value per hectare (AGRICPROX) to covariates of interest such as DENSITY, FRAG, and ARTIFAREA including squared terms. In all these preliminary models, we searched for Box-Cox transformations of AGRICPROX. All cases pointed unambiguously to the logarithmic transformation. Hence, in the following, we consider only log-linear models where $\log (A G R I C P R O X)$ is the dependent variable.

The BMA approach was applied to the list of covariates described in Table 1. Together, these 28 variables imply a complete model space of $2^{28}>250$ million models. Considering all the 28 variables together leaves us with 97 complete cases on which we apply the procedure. Using the Occam's window approach described previously, this space is reduced to only 69 models which are at least 20 times less probable than the best model. Together, the 5 best models have a posterior probability of 0.214 , which is not very high. This suggests that many candidate models are credible variants to the best alternative. The covariates selection is identical to that selected using the Markov chain Monte Carlo of model composition $\left(\mathrm{MC}^{3}\right)$ algorithm developed by Madigan et Raftery (1995). The covariates selection is also consistent with that of bootstrapped stepwise selection (Austin and Tu 2004) performed both ways using

\footnotetext{
${ }^{6}$ Appendix 1 lists the 208 cities included in our study and their geographical groupings.
} 
1000 bootstrapped samples on the same set of candidate covariates. The model selected by bootstrapped stepwise corresponds to the best model identified by BMA.

Table 2 summarizes the bayesian model average giving the posterior probability of inclusion of each covariate, its posterior mean, and variance. The three best models are also described. The posterior probabilities of the best and second best models are 0.056 and 0.051 respectively. Hence, the posterior odd in favor of the best model is only 1.10 . It is only 1.47 against the third best model. However, these three models are really similar in specification and the differences only relate to the addition of a squared term on MEDALT or on SAREA, and on the addition of income and farm yield variables.

Our variables of interest are included in all 69 models along with their squared terms, with the exception of DENSITY_2 which is included in $97 \%$ of the selected models. The posterior estimates for DENSITY and its corresponding quadratic term are positive and negative respectively, which implies a concave relationship between farm returns and density. ${ }^{7}$ The parameters on FRAG and $F R A G^{2}$ indicate an inverted U-shape relationship between farm returns and urban fragmentation. This is further discussed in the next section.

Contrary to $\mathrm{Wu}$ et al. (2011), we found some evidence of the impact of income, as measured by GDP_CAP, on farm returns. We used lagged GDP_CAP in 2000 to avoid endogeneity issues. Indeed, GDP_CAP is included in $64 \%$ of the 69 best models. The relationship between population income and farm returns is increasing and concave. None of the variables describing the city climate are significant. Similarly, accessibility of the city and urban amenities (CINEMA and GREENSPACE) have no impact on farm returns. This is also the case for our proxy for farmland quality $(Y C O R N)$.

\footnotetext{
${ }^{7}$ As in Wu et al. (2011), we used lagged density to avoid potential endogeneity issues. We used density measured in 2000. However, using density in 2006, the year of measurement of farm returns, doesn't change anything to the interpretation of the results.
} 
Table 1. Description of variables

\begin{tabular}{|c|c|c|c|c|c|}
\hline Variable & Units & Description & Cases & Mean & $\begin{array}{l}\text { Std. } \\
\text { Dev. }\end{array}$ \\
\hline AGRIPROX & $€ /$ ha & $\begin{array}{l}\text { Agricultural added value per hectare } \\
\text { (purchase power parity) }\end{array}$ & 208 & 6098 & 11002 \\
\hline $\mathrm{W}$ & Dummy & $\begin{array}{l}=1 \text { if western European city, } 0 \text { otherwise } \\
\text { (North taken as the reference) }\end{array}$ & 208 & 0.38 & 0.49 \\
\hline S & Dummy & $\begin{array}{l}=1 \text { if southern European city, } 0 \text { otherwise } \\
\text { (North taken as the reference) }\end{array}$ & 208 & 0.26 & 0.44 \\
\hline $\mathrm{E}$ & Dummy & $\begin{array}{l}=1 \text { if eastern European city, } 0 \text { otherwise } \\
\text { (North taken as the reference) }\end{array}$ & 208 & 0.30 & 0.46 \\
\hline SAREA & $1000 \mathrm{~km}^{2}$ & Surface area of the city & 208 & 2.08 & 2.09 \\
\hline SAREA_2 & - & SAREA squared & 208 & 8.69 & 25.71 \\
\hline ARTIFAREA & $1000 \mathrm{~km}^{2}$ & Artificialized surface area of the city & 208 & 0.24 & 0.28 \\
\hline ARTIFAREA_2 & - & ARTIFAREA squared & 208 & 0.14 & 0.53 \\
\hline DENSITY & $1000 \mathrm{inh} / \mathrm{km}^{2}$ & Inhabitants per $\mathrm{km}^{2}$ of ARTIFAREA & 208 & 6.07 & 4.10 \\
\hline DENSITY_2 & - & DENSITY squared & 208 & 53.61 & 76.75 \\
\hline FRAG & $\# / \mathrm{km}^{2}$ & $\begin{array}{l}\text { Number of fragments per } \mathrm{km}^{2} \text { of } \\
\text { ARTIFAREA }\end{array}$ & 208 & 0.44 & 0.25 \\
\hline FRAG_2 & - & SCATT squared & 208 & 0.25 & 0.27 \\
\hline GDP_CAP & $1000 € /$ capita & $\begin{array}{l}\text { GDP per capita in } 2000 \text { (purchase power } \\
\text { parity) }\end{array}$ & 208 & 18.55 & 8.85 \\
\hline GDP_CAP_2 & - & GDP_CAP squared & 208 & 421.99 & 361.74 \\
\hline YCORN & $\mathrm{kg} / \mathrm{ha}$ & $100 \mathrm{~kg}$ per hectare & 208 & 48.39 & 18.56 \\
\hline RAIN & \# & Number of rainy days in the year & 208 & 150.71 & 48.92 \\
\hline SUNSHINE & hrs. & Average hours of sunshine per day & 176 & 5.29 & 1.25 \\
\hline TEMPERATURE & ${ }^{\circ} \mathrm{C}$ & $\begin{array}{l}\text { Average temperature of the warmest } \\
\text { months in a year }\end{array}$ & 208 & 21.71 & 4.06 \\
\hline NO2 & $\mu \mathrm{g} / \mathrm{m}^{3}$ & Annual average concentration of NO2 & 166 & 28.11 & 10.73 \\
\hline HIGHWAY & $\mathrm{km} / \mathrm{km}^{2}$ & Length per surface area & 208 & 29.57 & 30.89 \\
\hline CRIME & \# / inh. & Number per 1000 inhabitants & 181 & 83.59 & 45.59 \\
\hline BURGLARY & \# / inh. & Number per 1000 inhabitants & 183 & 2.91 & 2.52 \\
\hline ACCESSAIR & Index & Normalized to 100 on the EU mean & 177 & 98.28 & 36.08 \\
\hline ACCESSRAIL & Index & Normalized to 100 on the EU mean & 172 & 94.12 & 65.47 \\
\hline ACCESSROAD & Index & Normalized to 100 on the EU mean & 173 & 92.77 & 58.13 \\
\hline CINEMA & \# / inh. & $\begin{array}{l}\text { Number of cinema seats per } 1000 \\
\text { inhabitants }\end{array}$ & 193 & 17.16 & 9.52 \\
\hline GREENSPACE & ha & Surface area in hectare & 156 & 41.38 & 56.94 \\
\hline MEDALT & 100 meters & $\begin{array}{l}\text { Median city center altitude above sea } \\
\text { level }\end{array}$ & 208 & 1.31 & 1.39 \\
\hline MEDALT_2 & - & MEDALT squared & 208 & 3.64 & 7.84 \\
\hline
\end{tabular}


Table 2. Bayesian Model Averaging Estimates (n=97)

\begin{tabular}{|c|c|c|c|c|c|c|c|c|c|}
\hline \multirow[b]{2}{*}{ Variable } & \multicolumn{3}{|c|}{ Bayesian Model Averaging } & \multicolumn{2}{|c|}{ Best Model } & \multicolumn{2}{|c|}{$2^{\text {nd }}$ Best Model } & \multicolumn{2}{|c|}{$3^{\text {rd }}$ Best Model } \\
\hline & $P(\hat{\beta} \neq 0)$ & $E(\hat{\beta} \mid \Phi)$ & $\operatorname{Var}(\hat{\beta} \mid \Phi)$ & Coef. & Std. Err. & Coef. & Std. Err. & Coef. & Std. Err. \\
\hline Constant & 100 & 7.01936 & 1.34326 & $8.35186^{\text {3**** }}$ & 0.48365 & $5.95350^{* * * * *}$ & 0.51586 & $8.37690^{* * 3 *}$ & 0.48811 \\
\hline $\mathrm{W}$ & 9.0 & -0.03759 & 0.14346 & & & & & & \\
\hline S & 89.9 & -0.66188 & 0.35932 & $-0.64888^{* *}$ & 0.23114 & $-0.70235^{* *}$ & 0.22911 & $-0.66483^{* *}$ & 0.23206 \\
\hline $\mathrm{E}$ & 63 & -0.68236 & 0.64495 & $-1.39102^{* * * *}$ & 0.20773 & & & $-1.35285^{* * *}$ & 0.20686 \\
\hline SAREA & 95.8 & -0.21478 & 0.10607 & $-0.07815^{* *}$ & 0.02565 & $-0.28634^{* * *}$ & 0.05726 & $-0.08626^{* *}$ & 0.02541 \\
\hline SAREA_2 & 76.3 & 0.00894 & 0.00644 & & & $0.01267^{* *}$ & 0.00384 & & \\
\hline ARTIFAREA & 2.4 & -0.01174 & 0.08036 & & & & & & \\
\hline ARTIFAREA_2 & 1.4 & -0.00288 & 0.02591 & & & & & & \\
\hline DENSITY & 100 & 0.47400 & 0.10082 & $0.52675^{* * *}$ & 0.08644 & $0.45343^{* * *}$ & 0.08296 & $0.53025^{* * *}$ & 0.08668 \\
\hline DENSITY_2 & 97.1 & -0.01713 & 0.00672 & $-0.02033^{* * *}$ & 0.00563 & $-0.01528^{* *}$ & 0.00543 & $-0.02079^{* * *}$ & 0.00563 \\
\hline FRAG & 100 & -4.41333 & 1.14789 & $-5.16838^{* * *}$ & 0.99977 & $-3.73602^{* * *}$ & 0.96583 & $-4.97025^{* * *}$ & 1.00357 \\
\hline FRAG_2 & 100 & 3.80594 & 1.05753 & $4.29763^{\text {**** }}$ & 0.99384 & $3.36377^{* * * *}$ & 0.94850 & $4.25005^{\text {*** }}$ & 0.99709 \\
\hline GDP_CAP & 64.1 & 0.11440 & 0.09776 & & & $0.22731^{* * *}$ & 0.03711 & & \\
\hline GDP_CAP_2 & 62.4 & -0.00189 & 0.00166 & & & $-0.00371^{* * *}$ & 0.00077 & & \\
\hline YCORN & 19.5 & -0.00226 & 0.00531 & & & $-0.01246^{*}$ & 0.00571 & & \\
\hline RAIN & 3.4 & -0.00008 & 0.00054 & & & & & & \\
\hline SUNSHINE & 13.6 & 0.01933 & 0.05683 & & & & & & \\
\hline TEMPERATURE & 0.0 & - & - & & & & & & \\
\hline $\mathrm{NO} 2$ & 0.0 & - & - & & & & & & \\
\hline HIGHWAY & 2.5 & 0.00007 & 0.00057 & & & & & & \\
\hline CRIME & 96.2 & -0.00678 & 0.00273 & $-0.00764^{* * *}$ & 0.00227 & $-0.00587^{* *}$ & 0.00210 & $-0.00742^{* *}$ & 0.00227 \\
\hline BURGLARY & 0.0 & - & - & & & & & & \\
\hline ACCESSAIR & 1.1 & 0.00003 & 0.00036 & & & & & & \\
\hline ACCESRAIL & 10.3 & -0.00027 & 0.00092 & & & & & & \\
\hline ACCESSROAD & 7.3 & -0.00023 & 0.00093 & & & & & & \\
\hline CINEMA & 4.1 & -0.00048 & 0.00294 & & & & & & \\
\hline GREENSPACE & 0.0 & - & - & & & & & & \\
\hline MEDALT & 45.8 & -0.07147 & 0.08426 & & & $-0.16104^{* * *}$ & 0.04574 & $-0.16747^{* * *}$ & 0.04692 \\
\hline MEDALT_2 & 54.2 & -0.01441 & 0.01454 & $-0.02878^{* * *}$ & 0.00783 & & & & \\
\hline$P\left(M_{k} \mid \Phi\right)$ & & & & & & & & & \\
\hline Adjusted-R ${ }^{2}$ & & & & & & & & & \\
\hline
\end{tabular}


With the exception of the regional dummies for Southern and Eastern countries and the covariates describing urban development, only CRIME and MEDALT make the selection in more than $40 \%$ of cases. We can relate the negative effects of these two variables to urban structure. Patacchini and Zenou (2009) show that European cities with more crime sprawl more. It may also be related to flight from blight phenomena where richer families would move to the city outskirts. These families may exert some social pressure on farmers hence increasing their costs. Darly and Torre (2013) give evidence for the Greater Paris region that these conflicts are important, especially in areas where residents convey an important value to farmland amenities. The negative impact of $M E D A L T$ can be related first to crop choices in rugged or mountainous areas where poor soils and steep slopes favor low income farming (extensive cattle) rather than high value crops (fruits, vegetables, or market crops like corn or maize). Moreover, MEDALT increases the cost of converting farmland to urban use which is higher in those areas. Commuting costs are also increased in hilly regions.

Most of the variables with a low posterior probability $(<10 \%$, see Table 2$)$ also have many missing observations. Thus, we can safely restrict the set of potential covariates. The results of a second BMA analysis are presented in Appendix 2 where we restrict to 20 covariates (hence $2^{20}>1$ million models) leaving us with 158 observations. We identify 28 models in the Occam's window and the 5 best models account for a cumulated posterior probability of 0.47 . Results are virtually identical to the BMA analysis presented in Table 2 except for Eastern countries dummy which are now included in the selection and SUNSHINE which is selected in almost half the models.

In addition to testing several model selection algorithms ( $\mathrm{MC}^{3}$, bootstrapped stepwise), we also tested the robustness ${ }^{8}$ of our results against potential endogeneity in the urban equilibrium covariates. First, we used lagged covariates (in 2000) for ARTIFAREA, DENSITY, and FRAG. The results are similar to that presented in Table 2 in terms of sign, significance, and magnitude of the estimated parameters. Second, we estimate the model using lagged covariates for ARTIFAREA, DENSITY, and FRAG in 2000 as instruments for the 2006 values. We also used the lagged values in 1990 as instrumental variables in another model check. The second-stage estimates are consistent with those presented in Table 2. An examination of the

\footnotetext{
${ }^{8}$ These robustness checks are available from authors upon request.
} 
first stage instrumental equations estimates suggests that lagged instruments are strong according to the F-test and partial $\mathrm{R}^{2}$ (Bound, Jaeger, and Baker, 1995). The exclusion of several covariates possibly related to urban equilibrium (ACCESS variables) in our restricted covariate set (Appendix 3) offers the possibility to estimate an overidentified model and test for endogeneity of the included covariates in the second-stage using a Hausman test. On this basis we rejected the endogeneity of 2006 covariates and thus the results presented in Table 2 constitute our preferred alternative.

The estimated models can be used to assess the impact of both fragmentation and density on farm returns. Using the BMA estimates presented in this paper, we can express farm returns as a function of both density and fragmentation:

$$
\hat{\pi}=f(\bar{X}, D E N S I T Y, F R A G)
$$

where $E(\hat{\beta} \mid \Phi)$ and all the covariates $\bar{X}$ are set at their sample mean except DENSITY and FRAG.

Figure 2 presents the results. Blue dots represent cities included in the sample. The left panel shows (13) for the complete covariates set (Table 2) while the right panel is established on the restricted covariates set (Appendix 3). Eq. (13) describes a saddle in the fragmentationdensity plane.

Increasing fragmentation reduces farm returns initially. However, as fragmentation reaches a certain threshold, further increases will lead to higher per-acre farm returns. The impact of fragmentation on farm returns is reinforced by increasing population density. At low population density levels, increased fragmentation barely affects farm returns. However, as population density increases, the effect of fragmentation increases.

At any level of fragmentation, increasing density increases farm returns when density is below 10,000 inhab. $/ \mathrm{km}^{2}$. Above this threshold, increasing density has a limited impact on farm returns, at least when land is moderately scattered. For low or high levels of fragmentation, increasing density above this threshold strongly increases farm returns. They decrease again for densities above 15,000 inhab. $/ \mathrm{km}^{2}$. Only a few cities in our sample have population density above 15,000 inhab./ $/ \mathrm{km}^{2}$. 


\section{POLICY IMPLICATIONS}

Our theoretical model shows that several dimensions of urbanization, including total developed areas, the level of fragmentation, and population density, may affect agricultural economies. These dimensions often have opposite effects. Thus, the total effect of urbanization on farm returns can either be positive or negative, depending on the relative magnitudes of the effects of these dimensions.

Our empirical application suggests that, at least in Europe, increasing population density will improve farm returns in the fringe of almost all cities. This result is in line with Wu et al. (2011), which studies the effect of urbanization in the United States. Fragmentation also affects farm returns, but in a non-linear fashion. Increasing fragmentation reduces farm returns initially. But when fragmentation reaches a certain threshold, further increases in fragmentation will increase farm returns. Currently, less than half of European cities have reached this threshold.

The nonlinear relationship between fragmentation and farm returns suggests that different policy strategies should be adopted to protect farm income in the fringe of cities with different levels of fragmentation and population densities. As shown in Figure 3, both the population densities and the level of fragmentation vary significantly across European cities. Cities in northern and western Europe tend to have low population densities and low fragmentation. In contrast, cities in southern and eastern Europe are much more eclectic in terms of population densities and spatial configurations.

Our results suggest that for cities with low population densities and low fragmentation, such as those located in northern Europe, anti-sprawl policies, for the benefits of farming, should concentrate on both density control and pattern management. In those cities, policies that encourage contiguous, dense development will increase farm returns. In contrast, for cities with highly fragmented urban development patterns, such as many of those located in eastern and southern Europe, anti-sprawl policies, for the benefits of farming, should concentrate on density management. In those cities, further fragmentation could potentially increase farm returns, particularly when the population density is also high. 

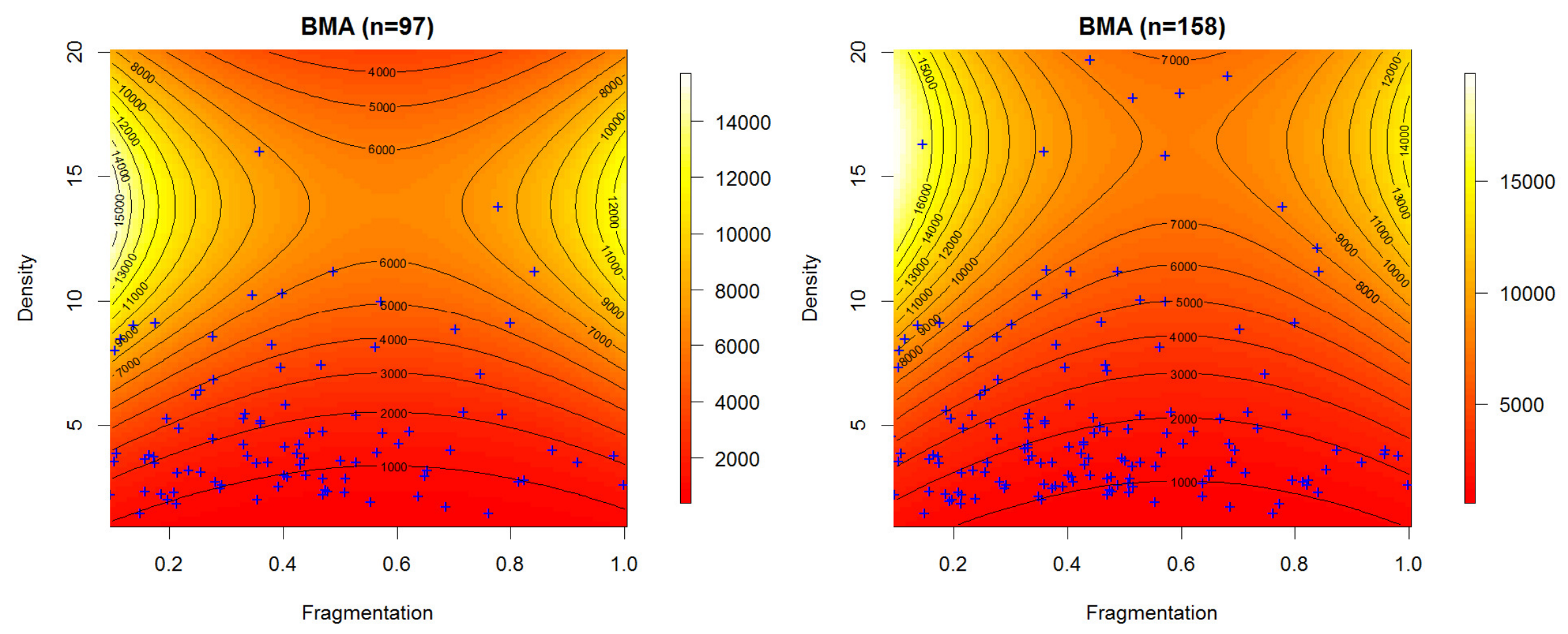

Figure 2. Effects of densification and fragmentation on farm returns 

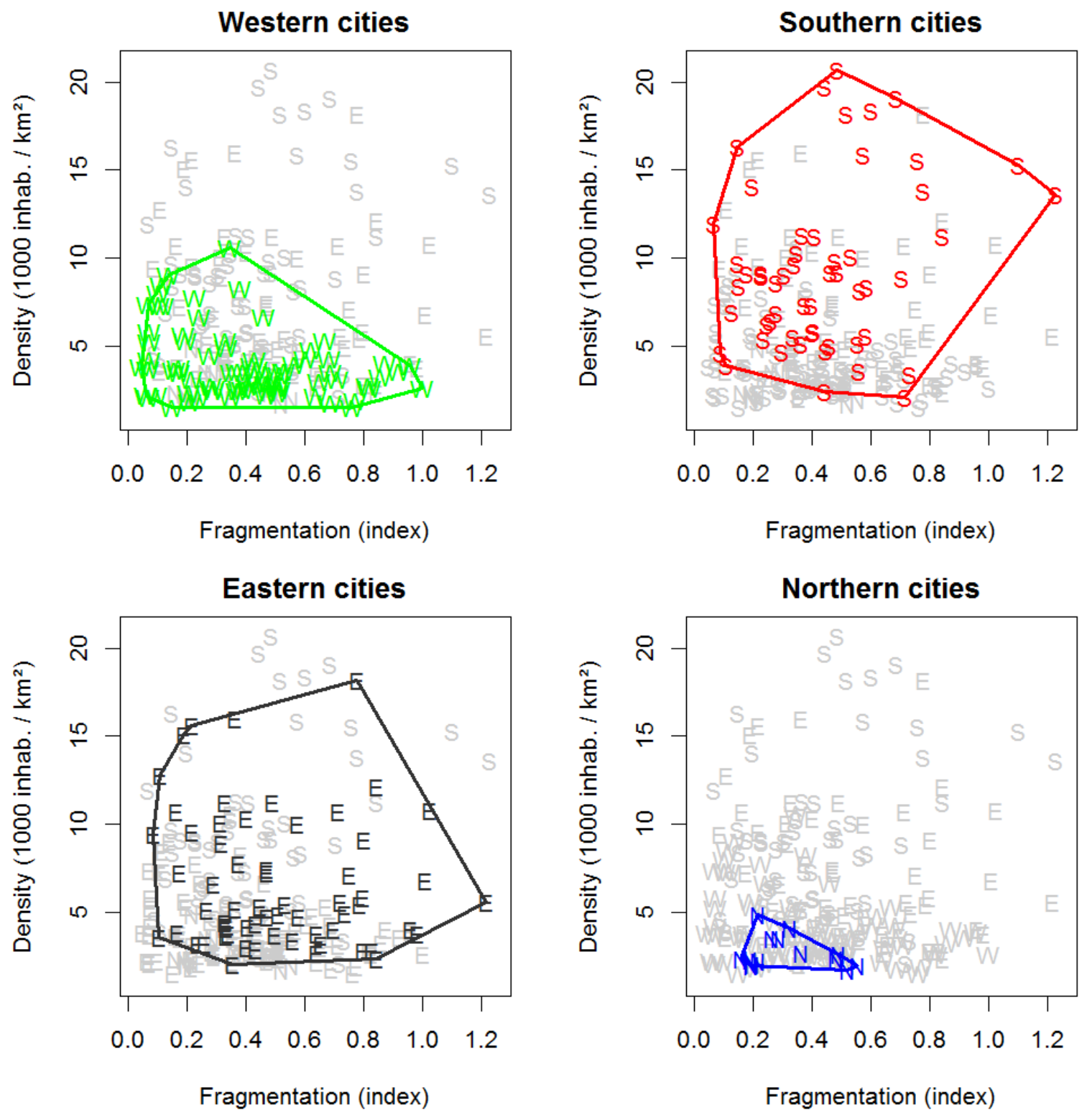

Note: W, S, E and N refer to Western, Southern, Eastern and Northern areas as described in Appendix 2. The 208 cities are represented on each panel.

Figure 3. European cities' geographical grouping (convex hulls) in the fragmentationdensity plane

As illustrated in Figure 4, for the protection of farm returns, urban development paths should follow the direction indicated by the arrows. For the two-way paths, moving toward either direction could increase farm returns, depending on the initial level of fragmentation and development density. 


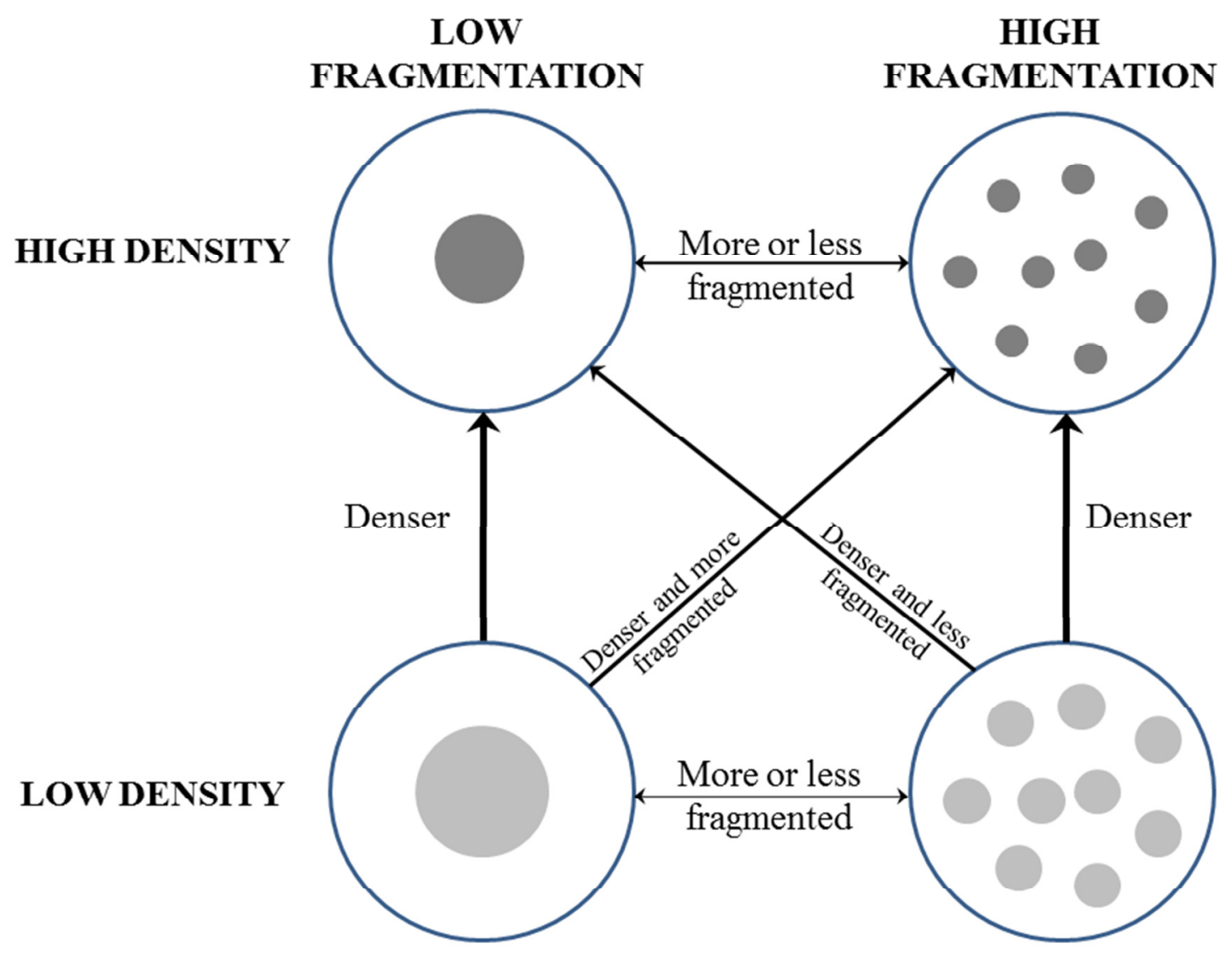

Note: Cities of the same size (large circles) and same population, but different population densities (darkening grays) and different levels of fragmentation. Arrows point in the direction of increased farm returns. Arrows' width is proportional to the importance of the effect.

\section{Figure 4. An illustration of densification and fragmentation on farm returns}

These results offer a renewed look at anti-sprawl policies. The justification for such policies usually stems from the inefficiencies arising from the lack of incentives for urban developers to fully account for environmental impacts, traffic congestion, and public services costs associated with their development (Brueckner, 2001). In this paper, we identify farm income protection as another motivation for anti-sprawl policies.

Urban growth control policies generally comprise a bulk of tools that may affect both population densities and development patterns. The main tools comprise setting urban growth boundaries, floor space controls (such as minimum lot size), infrastructure controls, zoning (like downzoning), and political controls requiring public approval. Quigley and Rosenthal (2005) propose a comprehensive review of these tools regarding their effects on housing prices. Geshkov and DeSalvo (2012) review their effects on cities' size. As shown by 
Geshkov and DeSalvo (2012), most of these policy measures are correlated, at least in the U.S. where they conduct their analysis. For example, counties setting up an urban growth boundary are also likely to enforce a minimum square footage regulation. They also show that urban growth boundaries and minimum square footage limits are not effective in limiting urban density. They find, however, that the other tools (maximum lot size, building permits limitations, or impact fees) are effective in controlling the spatial expansion of cities.

Literature is sparse on the effectiveness of alternative land-use regulations for controling fragmentation. Zoning may well be effective in controlling development inside the protected area, but may generate leapfrog development in the vicinity of the protected area (Irwin and Bockstael, 2004; Wu, 2006). This suggests that it may be difficult to control fragmentation. Fortunately, fragmentation does not significantly affect farm returns when population density is low. When population densities are high and urban development is highly fragmented, further fragmentation will likely enhance farm returns. This suggests that land use policy for protecting farmland and farm income should be set primarily on the basis of their effectiveness for controlling the density of development, rather than patterns of development.

\section{CONCLUSION}

Urbanization presents both opportunities and threats to the farming sector. On the one hand, it increases the customer base, and creates opportunities to grow high-value crops. On the other hand, it may increase both farmers' actual and opportunity costs of production. This paper constitutes a first attempt to capture, both theoretically and empirically, the effects of two dimensions of urbanization, increasing population density and increasing land fragmentation, on farm returns in EU countries.

While increasing population density will likely increasing farming returns for most European cities, urban fragmentation can have a positive or negative effect on farm returns, depending on the population density and the existing level of urban fragmentation. Although most European cities are still below the threshold of population density, above which further increases in population density will lead to lower farm returns, almost half of the European cities in our sample have already passed the fragmentation threshold, above which decreasing fragmentation will lead to lower agricultural productivity and lower farm returns. 
Our empirical application to European cities relies on a Bayesian model averaging approach which explicitly accounts for model uncertainty in describing farm returns. Our estimates show that the data at hand strongly support the hypothesis that both urbanization dimensions affect farm returns. However, farm returns are more sensitive to population density than to urban fragmentation, at least at low and medium density levels. In line with Wu et al. (2011), who analyzes the effect of urbanization on U.S. agriculture, we show that increasing population density improves farm returns. Farm returns are more sensitive to urban fragmentation in densely populated areas than in sparsely populated areas.

Our results suggest that urban planning policies influencing population density and urban fragmentation will affect agricultural productivity and farm net returns. Specifically, policies that increase population density and, at the same time, prevent urban fragmentation will increase agricultural productivity and farm net returns in compactly developed areas. However, there is a lack of literature on this subject. Further research is needed to fill the knowledge gap and to better coordinate land use policies for urban growth management and rural development. 


\section{REFERENCES}

Amini, S.M. \& Parmeter, C.F. (2011). Bayesian model averaging in R. Journal of Economic and Social Measurement, 36, 253-287.

Austin, P.C., \& Tu, J.V. (2004). Bootstrap methods for developing predictive models. The American Statistician, 58(2), 131-137.

Brueckner, J.K. (2001). Urban sprawl: Lessons from urban economics [with comments]. Brookings-Wharton papers on urban affairs, 65-97.

Bound, J., Jaeger, D.A., \& Baker, R.M. (1995). Problems with instrumental variables estimation when the correlation between the instruments and the endogenous explanatory variable is weak. Journal of the American statistical association, 90(430), 443-450.

Capozza, D.R., \& Helsley, R.W. (1989). The Fundamentals of Land Prices and Urban Growth. Journal of Urban Economics, 26(3), 295-306.

Capozza, D.R., \& Helsley, R.W. (1990). The stochastic city. Journal of Urban Economics, 28(2), 187-203.

Cavailhès, J., \& Wavresky, P. (2003). Urban Influences on Periurban Farmland Prices. European Review of Agricultural Economics, 30(3), 333-357.

Darly, S., \& Torre, A. (2013). Conflicts over farmland uses and the dynamics of "agri-urban" localities in the Greater Paris Region: An empirical analysis based on daily regional press and field interviews. Land Use Policy, 33, 90-99.

Duvivier, C. (2013). Does urban proximity enhance technical efficiency? Evidence from Chinese agriculture. Journal of Regional Science, 53(5), 923-943.

EEA - European Environmental Agency. (2006). Urban Sprawl in Europe: The Ignored Challenge. European Commission Joint Research Centre.

EUROSTAT (2004). Urban Audit. Methodological Handbook. European Commission, 2004 edition.

Gardner, B. L. (1994). Commercial agriculture in metropolitan areas: Economics and regulatory issues. Agricultural and Resource Economics Review, 23(1), 100-109.

Geshkov, M.V., \& DeSalvo, J.S. (2012). The effect of land-use controls on the spatial size of U.S. urbanized areas. Journal of Regional Science, 52(4), 648-675.

Hoeting, J.A., Madigan, J., Raftery, A.E., \& Volinsky C.T. (1999). Bayesian Model Averaging: A Tutorial. Statistical Science, 14(4), 382-417.

Irwin, E.G., \& Bockstael, N.E. (2004). Land use externalities, open space preservation, and urban sprawl. Regional Science and Urban Economics, 34(6), 705-725 
Kass, R.E. \& Raftery, A.E. (1995). Bayes Factors. Journal of the American Statistical Association, 90(430), 773-795

Kass, R. E., \& Wasserman, L. (1995). A reference Bayesian test for nested hypotheses and its relationship to the Schwarz criterion. Journal of the American Statistical Association, 90(431), 928-934.

Larson, J. M., Findeis, J. L., \& Smith, S. M. (2001). Agricultural adaptation to urbanization in southeastern Pennsylvania. Agricultural and Resource Economics Review, 30(1), 32-43.

Lisansky, J. (1986). Farming in an urbanizing environment: Agricultural land use conflicts and right to farm. Human Organization, 45(4), 363-371.

Livanis, G., Moss, C.B., Breneman, V.E., \& Nehring, R.F. (2006). Urban Sprawl and Farmland Prices. American Journal of Agricultural Economics, 88(4), 915-929.

Lockeretz, W. (1986). Trends in farming near cities. Journal of Soil and Water Conservation, 41(4), 256-262.

Lockeretz, W. (1989). Secondary Effects on Midwestern Agriculture of Metropolitan Development and Decreases in Farmland. Land Economics, 65(3), 205-216.

Lopez, R.A., Adelaja, A.O., \& Andrews, M.S. (1988). The effects of suburbanization on agriculture. American Journal of Agricultural Economics, 70(2), 346-358.

Lynch, L., \& Carpenter, J. (2003). Is there evidence of a critical mass in the Mid-Atlantic agriculture sector between 1949 and 1997? Agricultural and Resource Economics Review, 32(1), 116-128.

Lynch, L. (2006). Critical Mass: Does the Number of Productive Farmland Acres or of Farms Affect Farmland Loss? In Economics and Contemporary Land Use Policy: Development and Conservation at the Rural-Urban Fringe, ed. Robert J. Johnston and Stephen K. Swallow, 149-69.Washington, DC: Resources for the Future.

Madigan, D. \& Raftery, A.E. (1994). Model selection and accounting for model uncertainty in graphical models using Occam's window. Journal of the American Statistical Association, 89(428), 1535-1546.

Madigan, D., \& York, J. (1995). Bayesian graphical models for discrete data. International Statistical Review, 215-232.

Patacchini, E., \& Zenou, Y. (2009). Urban sprawl in Europe. Brookings-Wharton Papers on Urban Affairs, 2009(1), 125-149.

Plantinga, A.J., Lubowski, R.N., \& Stavins, R.N. (2002). The Effects of Potential Land Development on Agricultural Land Prices. Journal of Urban Economics, 52(3), 561581 .

Raftery, A. E. (1995). Bayesian model selection in social research. Sociological Methodology, 25, 111-164. 
Raftery, A.E., Madigan D., \& Hoeting, J.A. (1997). Bayesian Model Averaging for Linear Regression Models. Journal of the American Statistical Association, 92(437), 179-191.

Rashford, B.S., Lewis, D.J., Evonuk, R.M. \& Weber, B.A. (2003). Economic Interrelationships in a Small Farming Area: Towards an Estimate of the Threshold of Agricultural Production for Sustainable Agriculture. Working Paper No. AREC 03101.

Quigley, J.M., \& Rosenthal, L.A. (2005). The effects of land use regulation on the price of housing: What do we know? What can we learn? Cityscape, 8(1), 69-137.

Wasserman, L. (2000). Bayesian model selection and model averaging. Journal of Mathematical Phsychology, 44, 92-107.

Wu, J.J. (2006) "Environmental Amenities, Urban Sprawl, and Community Characteristics." Journal of Environmental Economics and Management. 52, 527-547.

Wu, J.J., \& Lin, H. (2010). The Effect of the Conservation Reserve Program on Land Values. Land Economics, 86(1), 1-21.

Wu, J.J., Fisher, M., \& Pascual, U. (2011). Urbanization and the viability of local agricultural economies. Land Economics, 87(1), 109-125. 


\section{APPENDIX 1. Proofs}

\section{Proof of Proposition 1.}

Differentiating equations (1)-(4) with respect to $S$, we obtain:

$$
\begin{aligned}
& \frac{\partial A_{c}}{\partial S}+\frac{\partial A_{v}}{\partial S}=0 \\
& y_{v} \frac{\partial A_{v}}{\partial S}+A_{v} \frac{\partial y_{v}}{\partial p_{v}} \frac{\partial p_{v}}{\partial S}+A_{v} \frac{\partial y_{v}}{\partial w_{v}} \frac{\partial w_{v}}{\partial S}=\frac{\partial Y_{v}^{d}}{\partial p_{v}} \frac{\partial p_{v}}{\partial S}, \\
& x_{v} \frac{\partial A_{v}}{\partial S}+A_{v} \frac{\partial x_{v}}{\partial p_{v}} \frac{\partial p_{v}}{\partial S}+A_{v} \frac{\partial x_{v}}{\partial w_{v}} \frac{\partial w_{v}}{\partial S}=\frac{\partial X_{v}^{s}}{\partial w_{v}} \frac{\partial w_{v}}{\partial S}, \\
& x_{c} \frac{\partial A_{c}}{\partial S}+A_{c} \frac{\partial x_{c}}{\partial w_{c}} \frac{\partial w_{c}}{\partial S}=\frac{\partial X_{c}^{S}}{\partial w_{c}} \frac{\partial w_{c}}{\partial S}, \\
& y_{v} \frac{\partial p_{v}}{\partial S}-x_{v} \frac{\partial w_{v}}{\partial S}+x_{c} \frac{\partial w_{c}}{\partial S}=\Delta^{\prime}(S),
\end{aligned}
$$

Substituting [1A] into [3A], re-arranging and rewriting in the matrix format, we obtain:

$$
\left(\begin{array}{cccc}
0 & y_{v} & -x_{v} & x_{c} \\
y_{v} & a_{11} & a_{12} & 0 \\
-x_{v} & a_{12} & a_{22} & 0 \\
x_{c} & 0 & 0 & b_{22}
\end{array}\right)\left(\begin{array}{c}
\frac{\partial A_{v}}{\partial S} \\
\frac{\partial p_{v}}{\partial S} \\
\frac{\partial w_{v}}{\partial S} \\
\frac{\partial w_{c}}{\partial S}
\end{array}\right)=\left(\begin{array}{c}
\Delta^{\prime}(S) \\
0 \\
0 \\
0
\end{array}\right),
$$

where

$$
\begin{array}{ll}
a_{11}=\left(A_{v} \frac{\partial y_{v}}{\partial p_{v}}-\frac{\partial Y_{v}^{d}}{\partial p_{v}}\right)>0 & a_{12}=A_{v} \frac{\partial y_{v}}{\partial w_{v}}<0 \\
a_{22}=\left(-A_{v} \frac{\partial x_{v}}{\partial w_{v}}+\frac{\partial X_{v}^{s}}{\partial w_{v}}\right)>0 & b_{22}=\left(-A_{c} \frac{\partial X_{c}}{\partial w_{c}}+\frac{\partial X_{c}^{s}}{\partial w_{c}}\right)>0
\end{array}
$$

Solving the equation system using Cramer's rule, we obtain:

$$
\frac{\partial A_{v}}{\partial S}=\frac{\Delta^{\prime}(S)}{\mid \downarrow} b_{22}\left|H_{2}\right| \geq 0 \text { iff } \Delta^{\prime}(S) \leq 0,
$$

where $\mid \mathcal{J}$ is determinant of the coefficient matrix (i.e., the $4 \times 4$ matrix) in $[6 \mathrm{~A}]$, which, as shown below, is negative; and $H_{2}$ is a $2 \times 2$ matrix whose determinant is positive (i.e., $\left|H_{2}\right|$ $>0$ ).

From [6A]: 


$$
\left|\mathcal{J}=-b_{22}\right| H_{3}\left|-x_{c}^{2}\right| H_{2} \mid
$$

where

$$
\begin{aligned}
& \left|H_{3}\right|=\frac{|\bar{H}|}{A_{v}^{2}}+\left(X_{v} \frac{\partial Y_{c}^{d}}{\partial p_{v}}-y_{v}^{2} \frac{\partial X_{v}^{s}}{\partial w_{v}}\right)<0, \\
& \left|H_{2}\right|=|H|+A_{v} \frac{\partial y_{v}}{\partial p_{v}} \frac{\partial X_{v}^{s}}{\partial w_{v}}+\frac{\partial Y_{c}^{d}}{\partial p_{v}} b_{22}>0 .
\end{aligned}
$$

In the above expressions, $|\bar{H}|$ is the determinant of the bordered Hessian of $A_{v} \pi_{v}\left(p_{v}, w_{v}\right)$, which is negative because $A_{v} \pi_{v}\left(p_{v}, w_{v}\right)$ is convex; and $|H|$ is the Hessian matrix of $A \pi_{v}\left(p_{v}, w_{v}\right)$, which is positive because of the convexity of $A \pi_{v}\left(p_{v}, w_{v}\right)$.

Likewise, solving the equation system [5A] using Cramer's rule, we can also obtain:

$$
\begin{aligned}
& \frac{\partial p_{v}}{\partial S}=\frac{-\Delta^{\prime}(S)}{|J|} b_{22}\left(\frac{A_{v} x_{v} y_{v}}{w_{v}}\left(\varepsilon_{w_{v}}^{x_{v}}-\varepsilon_{w_{v}}^{y_{v}}\right)+y_{v} \frac{\partial X_{v}^{S}}{\partial w_{v}}\right) \leq 0 \text { iff } \Delta^{\prime}(S) \leq 0 . \\
& \frac{\partial w_{v}}{\partial S}=\frac{\Delta^{\prime}(S)}{\mid J} b_{22}\left(\frac{A_{v} x_{v} y_{v}}{p_{v}}\left(\varepsilon_{p_{v}}^{y_{v}}-\varepsilon_{p_{v}}^{x_{v}}\right)-x_{v} \frac{\partial Y_{v}^{d}}{\partial p_{v}}\right) \geq 0 \text { iff } \Delta^{\prime}(S) \leq 0 . \\
& \frac{\partial w_{c}}{\partial S}=\frac{-\Delta^{\prime}(S)}{|J|} x_{c}\left|H_{2}\right| \leq 0 \text { iff } \Delta^{\prime}(S) \leq 0 .
\end{aligned}
$$

\section{Proof of Proposition 2.}

Differentiating equation (1)-(4) with respect to $U$, we obtain:

$$
\begin{aligned}
& \frac{\partial A_{c}}{\partial U}+\frac{\partial A_{v}}{\partial U}=-1 \\
& y_{v} \frac{\partial A_{v}}{\partial U}+A_{v} \frac{\partial y_{v}}{\partial p_{v}} \frac{\partial p_{v}}{\partial U}+A_{v} \frac{\partial y_{v}}{\partial w_{v}} \frac{\partial w_{v}}{\partial U}=\frac{\partial Y_{v}^{d}}{\partial p_{v}} \frac{\partial p_{v}}{\partial U}+\frac{\partial Y_{v}^{d}}{\partial U}, \\
& x_{v} \frac{\partial A_{v}}{\partial U}+A_{v} \frac{\partial x_{v}}{\partial p_{v}} \frac{\partial p_{v}}{\partial U}+A_{v} \frac{\partial x_{v}}{\partial w_{v}} \frac{\partial w_{v}}{\partial U}=\frac{\partial X_{v}^{s}}{\partial w_{v}} \frac{\partial w_{v}}{\partial U}, \\
& x_{c} \frac{\partial A_{c}}{\partial U}+A_{c} \frac{\partial x_{c}}{\partial w_{c}} \frac{\partial w_{c}}{\partial U}=\frac{\partial X_{c}^{s}}{\partial w_{c}} \frac{\partial w_{c}}{\partial U}, \\
& y_{v} \frac{\partial p_{v}}{\partial U}-x_{v} \frac{\partial w_{v}}{\partial U}+x_{c} \frac{\partial w_{c}}{\partial U}=0,
\end{aligned}
$$

Substituting [1A'] into [4A'], re-arranging, and rewriting in the matrix format, we obtain: 


$$
\left(\begin{array}{cccc}
0 & y_{v} & -x_{v} & x_{c} \\
y_{v} & a_{11} & a_{12} & 0 \\
-x_{v} & a_{12} & a_{22} & 0 \\
x_{c} & 0 & 0 & b_{22}
\end{array}\right)\left(\begin{array}{c}
\frac{\partial A_{v}}{\partial U} \\
\frac{\partial p_{v}}{\partial U} \\
\frac{\partial w_{v}}{\partial U} \\
\frac{\partial w_{c}}{\partial U}
\end{array}\right)=\left(\begin{array}{c}
0 \\
\frac{\partial Y_{v}^{d}}{\partial U} \\
0 \\
-x_{c}
\end{array}\right)
$$

Solving the equation system using Cramer's rule, we obtain:

$$
\begin{aligned}
& \frac{\partial A_{v}}{\partial U}=-\frac{1}{|\mathcal{J}|}\left[b_{22} \frac{\partial Y_{v}^{d}}{\partial U}\left(\frac{A_{v} X_{v} y_{v}}{w_{v}}\left(\varepsilon_{w_{v}}^{x_{v}}-\varepsilon_{w_{v}}^{v_{v}}\right)+y_{v} \frac{\partial X_{v}^{s}}{\partial w_{v}}\right)+x_{c}^{2}\left|H_{2}\right|\right] \geq 0 . \\
& \frac{\partial p_{v}}{\partial U}=-\frac{1}{|\mathcal{J}|}\left[\left(b_{22} x_{v}^{2}+a_{22} x_{c}^{2}\right) \frac{\partial Y_{v}^{d}}{\partial U}+A_{v} x_{c}^{2} x_{v} y_{v}\left(\left(\varepsilon_{w_{v}}^{x_{v}}-\varepsilon_{w_{v}}^{y_{v}}\right)+y_{v} \frac{\partial X_{v}^{d}}{\partial w_{v}}\right)\right] \geq 0 .
\end{aligned}
$$

From [3A'] and [4A']

$$
\begin{gathered}
\frac{\partial w_{v}}{\partial U}=\frac{x_{v} \frac{\partial A_{v}}{\partial U}+A_{v} \frac{\partial x_{v}}{\partial p_{v}} \frac{\partial p_{v}}{\partial U}}{\frac{\partial X_{v}^{s}}{\partial w_{v}}-A_{v} \frac{\partial x_{v}}{\partial w_{v}}}>0, \\
\frac{\partial w_{c}}{\partial U}=\frac{x_{c} \frac{\partial A_{c}}{\partial U}}{\frac{\partial X_{c}^{s}}{\partial w_{c}}-A_{c} \frac{\partial x_{c}}{\partial w_{c}}}<0 .
\end{gathered}
$$

Proof of Proposition 3.

The proof is similar to the proof of proposition 2 and is thus omitted. 


\section{APPENDIX 2. List of the 208 European cities.}

\begin{tabular}{|c|c|c|c|}
\hline Country & $\begin{array}{l}\text { \# of } \\
\text { cities }\end{array}$ & Group & Cities \\
\hline Austria & 5 & $\mathrm{~W}$ & Wien, Graz, Linz, Salzburg, Innsbruck \\
\hline Belgium & 7 & $\mathrm{~W}$ & Brussels, Antwerpen, Gent, Charleroi, Liege, Brugge, Namur \\
\hline Bulgaria & 6 & $\mathrm{E}$ & Sofia, Plovdiv, Varna, Burgas, Pleven, Ruse, Vidin \\
\hline Czech Republic & 5 & $\mathrm{E}$ & Praha, Brno, Ostrava, Olomouc, Zlin \\
\hline Denmark & 4 & $\mathrm{~N}$ & Kobenhavn, Aarhus, Odense, Aalborg \\
\hline Estonia & 2 & $\mathrm{E}$ & Tallinn, Tartu \\
\hline Finland & 3 & $\mathrm{~N}$ & Helsinki, Tampere, Oulu \\
\hline France & 20 & $\mathrm{~W}$ & $\begin{array}{l}\text { Paris, Marseille-Aix-en-Provence, Lyon, Toulouse, Nice, } \\
\text { Strasbourg, Bordeaux, Nantes, Lille, Rennes, Toulon, Tours, } \\
\text { Nancy, Metz, Dijon, Poitiers, Caen, Limoges, Besancon, Ajaccio }\end{array}$ \\
\hline Germany & 29 & $\mathrm{~W}$ & $\begin{array}{l}\text { Berlin, Hamburg, Munchen, Koln, Frankfurt am Main, Stuttgart, } \\
\text { Leipzig, Dresden, Dusseldorf, Bremen, Hannover, Nurnberg, } \\
\text { Wuppertal, Bielefeld, Halle an der Saale, Magdeburg, Wiesbaden, } \\
\text { Gottingen, Darmstadt, Trier, Freiburg im Breisgau, Regensburg, } \\
\text { Erfurt, Augsburg, Bonn, Monchengladbach, Mainz, Saarbrucken, } \\
\text { Koblenz }\end{array}$ \\
\hline Hungary & 7 & $\mathrm{E}$ & Budapest, Miskolc, Nyiregyhaza, Pecs, Debrecen, Szeged, Gyor \\
\hline Ireland & 3 & $\mathrm{~N}$ & Dublin, Cork, Limerick \\
\hline Italy & 29 & $\mathrm{~S}$ & $\begin{array}{l}\text { Roma, Milano, Napoli, Torino, Palermo, Genova, Firenze, Bari, } \\
\text { Bologna, Catania, Venezia, Verona, Trento, Trieste, Perugia, } \\
\text { Ancona, Pescara, Campobasso, Caserta, Taranto, Potenza, } \\
\text { Catanzaro, Reggio di Calabria, Sassari, Cagliari, Padova, Modena, } \\
\text { Foggia, Salerno }\end{array}$ \\
\hline Latvia & 1 & $\mathrm{E}$ & Riga \\
\hline Lithuania & 3 & $\mathrm{E}$ & Vilnius, Kaunas, Panevezys \\
\hline Luxembourg & 1 & $\mathrm{~W}$ & Luxembourg \\
\hline Malta & 2 & $\mathrm{~S}$ & Valletta, Gozo \\
\hline Netherlands & 12 & $\mathrm{~W}$ & $\begin{array}{l}\text { Amsterdam, Rotterdam, Utrecht, Eindhoven, s' Gravenhage, } \\
\text { Tilburg, Groningen, Enschede, Heerlen, Breda, Apeldoorn, } \\
\text { Leeuwarden }\end{array}$ \\
\hline Poland & 21 & $\mathrm{E}$ & $\begin{array}{l}\text { Warszawa, Lodz, Krakow, Wroclaw, Poznan, Gdansk, Szczecin, } \\
\text { Bydgoszcz, Lublin, Katowice, Kielce, Torun, Olsztyn, Rzeszow, } \\
\text { Opole, Gorzow Wielkopolski, Zielona Gora, Nowy Sacz, Konin, } \\
\text { Kalisz, Koszalin }\end{array}$ \\
\hline Portugal & 4 & $\mathrm{~S}$ & Lisboa, Oporto, Coimbra, Faro \\
\hline Romania & 12 & $\mathrm{E}$ & $\begin{array}{l}\text { Bucuresti, Cluj Napoca, Timisoara, Craiova, Braila, Oradea, } \\
\text { Bacau, Arad, Sibiu, Targu Mures, Piatra Neamt, Alba Iulia }\end{array}$ \\
\hline Slovakia & 5 & $\mathrm{E}$ & Bratislava, Kosice, Banska Bystrica, Presov, Zilina \\
\hline Slovenia & 2 & $\mathrm{~S}$ & Ljubljana, Maribor \\
\hline Spain & 17 & $\mathrm{~S}$ & $\begin{array}{l}\text { Madrid, Barcelona, Valencia, Sevilla, Zaragoza, Malaga, Murcia, } \\
\text { Las Palmas, Palma di Mallorca, Santiago de Compostela, } \\
\text { Pamplona/Iruna, Badajoz, Logrono, Cordoba, Alicante, Vigo, } \\
\text { Santa Cruz de Tenerife }\end{array}$ \\
\hline Sweden & 7 & $\mathrm{~N}$ & $\begin{array}{l}\text { Stockholm, Goteborg, Malmo, Jonkoping, Umea, Linkoping, } \\
\text { Orebro }\end{array}$ \\
\hline United-Kingdom & 1 & $\mathrm{~W}$ & Derry \\
\hline
\end{tabular}

Note: W,N,E,S relate to our geographical dummies described in Table 1. 
APPENDIX 3. Bayesian Model Averaging Estimates on the restricted subset of covariates (n=158)

\begin{tabular}{|c|c|c|c|c|c|c|c|c|c|}
\hline \multirow[b]{2}{*}{ Variable } & \multicolumn{3}{|c|}{ Bayesian Model Averaging } & \multicolumn{2}{|c|}{ Best Model } & \multicolumn{2}{|c|}{$2^{2^{\text {nd }}}$ Best Model } & \multicolumn{2}{|c|}{ 3 $^{\text {rd }}$ Best Model } \\
\hline & $P(\hat{\beta} \neq 0)$ & $E(\hat{\beta} \mid \Phi)$ & $\operatorname{Var}(\hat{\beta} \mid \Phi)$ & Coef. & Std. Err. & Coef. & Std. Err. & Coef. & Std. Err. \\
\hline Constant & 100 & 7.63937 & 0.78610 & $7.19869^{\text {***:* }}$ & 0.69454 & $7.20816^{3 * * *}$ & 0.69506 & $8.16411^{* * * *}$ & 0.57247 \\
\hline W & 98.4 & -0.78796 & 0.24131 & $-0.85203^{* * * *}$ & 0.20796 & $-0.82299^{* * *}$ & 0.20939 & $-0.87402^{* * *}$ & 0.21109 \\
\hline $\mathrm{S}$ & 100 & -1.50699 & 0.32623 & $-1.65520^{* * *}$ & 0.29744 & $-1.62107^{* * *}$ & 0.29872 & $-1.42957^{* * *}$ & 0.28641 \\
\hline $\mathrm{E}$ & 99.3 & -1.15194 & 0.32747 & $-1.21422^{* * *}$ & 0.29347 & $-1.15740^{* * * *}$ & 0.29525 & $-1.29829^{* * * *}$ & 0.29600 \\
\hline SAREA & 99.1 & -0.28116 & 0.06887 & $-0.29484^{* * * *}$ & 0.05828 & $-0.30046^{* * *}$ & 0.05807 & $-0.29201^{* * * *}$ & 0.05920 \\
\hline SAREA_2 & 99.1 & 0.01499 & 0.00444 & $0.01501^{* * *}$ & 0.00408 & $0.01508^{* * *}$ & 0.00408 & $0.01495^{* * *}$ & 0.00414 \\
\hline ARTIFAREA & 21.5 & -0.10758 & 0.24813 & & & & & & \\
\hline ARTIFAREA_2 & 10.9 & -0.01818 & 0.06535 & & & & & & \\
\hline DENSITY - & 100 & 0.36332 & 0.05188 & $0.36214^{* * * *}$ & 0.04991 & $0.35794^{* * *}$ & 0.04990 & $0.35798^{* * * *}$ & 0.05068 \\
\hline DENSITY_2 & 100 & -0.01107 & 0.00243 & $-0.01108^{* * * *}$ & 0.00237 & $-0.01096^{* * *}$ & 0.00238 & $-0.01084^{* * *}$ & 0.00241 \\
\hline FRAG & 100 & -4.47388 & 0.89597 & $-4.33725^{* * *}$ & 0.84720 & $-4.19779^{* * *}$ & 0.85237 & $-4.52140^{* * * *}$ & 0.85717 \\
\hline FRAG_2 & 100 & 3.75300 & 0.84183 & $3.66944^{* * *}$ & 0.81804 & $3.59959^{* * * *}$ & 0.81973 & $3.74943^{* * * *}$ & 0.83044 \\
\hline GDP_CAP & 100 & 0.15077 & 0.03766 & $0.14743^{* * * *}$ & 0.03617 & $0.14949^{* * * *}$ & 0.03626 & $0.14249^{* * * *}$ & 0.03669 \\
\hline GDP_CAP_2 & 100 & -0.00259 & 0.00070 & $-0.00255^{* * *}$ & 0.00068 & $-0.00258^{* * *}$ & 0.00068 & $-0.00252^{* * * *}$ & 0.00069 \\
\hline YCORN & 24.4 & -0.00214 & 0.00440 & & & & & & \\
\hline RAIN & 3.5 & -0.00006 & 0.00039 & & & & & & \\
\hline SUNSHINE & 50.6 & 0.07238 & 0.08400 & $0.13955^{*}$ & 0.05870 & $0.13656^{*}$ & 0.05880 & & \\
\hline TEMPERATURE & 4.5 & -0.00112 & 0.00728 & & & & & & \\
\hline CRIME & 100 & -0.00834 & 0.00193 & $-0.00826^{* * *}$ & 0.00182 & $-0.00827^{* * *}$ & 0.00182 & $-0.00935^{* * *}$ & 0.00179 \\
\hline MEDALT & 42 & -0.04665 & 0.06057 & & & $-0.10631^{* *}$ & 0.03906 & & \\
\hline MEDALT_2 & 53.8 & -0.01061 & 0.01106 & $-0.01879^{* *}$ & 0.00678 & & & $-0.01923^{* *}$ & 0.00688 \\
\hline$P\left(M_{k} \mid \Phi\right)$ & & & & & & & & & \\
\hline Adjusted-R ${ }^{2}$ & & & & & & & & & \\
\hline
\end{tabular}

,${ }^{* * *}$ : significance at the $1 \%, 5 \%$ and $10 \%$ levels respectively. 